\title{
Ten quality criteria of the public spaces in a large city
}

\author{
Ludmila Kozlova, ${ }^{1, *}$, Valery Kozlov ${ }^{1}$ \\ ${ }^{1}$ Irkutsk National Research Technical University, 83 Lermontov St., Irkutsk, 664074, Russia.
}

\begin{abstract}
Based on the world experience and features of the development of modern society, authors identified ten quality indicators, which are the principles of improvement and the criteria for assessing the public spaces of a large city. Based on the assessment of the distinctive public spaces of Irkutsk by these criteria have been identified qualities that require special attention in each case study and the general principles of improving the public spaces of the historic city center.
\end{abstract}

\section{Introduction}

A public space is a social space that is generally open and accessible to people. The quality of public spaces is estimated on the scale of a pedestrian and determines the intensity of use - accessibility, comfortable conditions to cross and inviting to sit and have a rest [1]. Studies directly or indirectly concerning the issue of public spaces describe their qualitative characteristics $[2,3,4,5,6,7]$. Based on the world experience and features of the development of modern society author identified ten quality indicators, which are the principles of improvement and the criteria for assessing the public spaces of a large city (Figure 1).

\section{Matherials and methods}

During the research, the following methods were used: general methods (analysis, synthesis, induction, analogy), theoretical methods (abstraction, historical and systemic approaches), empirical methods (observation, description, counting, comparison) [8].

\footnotetext{
* Corresponding author: koza-mila@ yandex.ru
} 

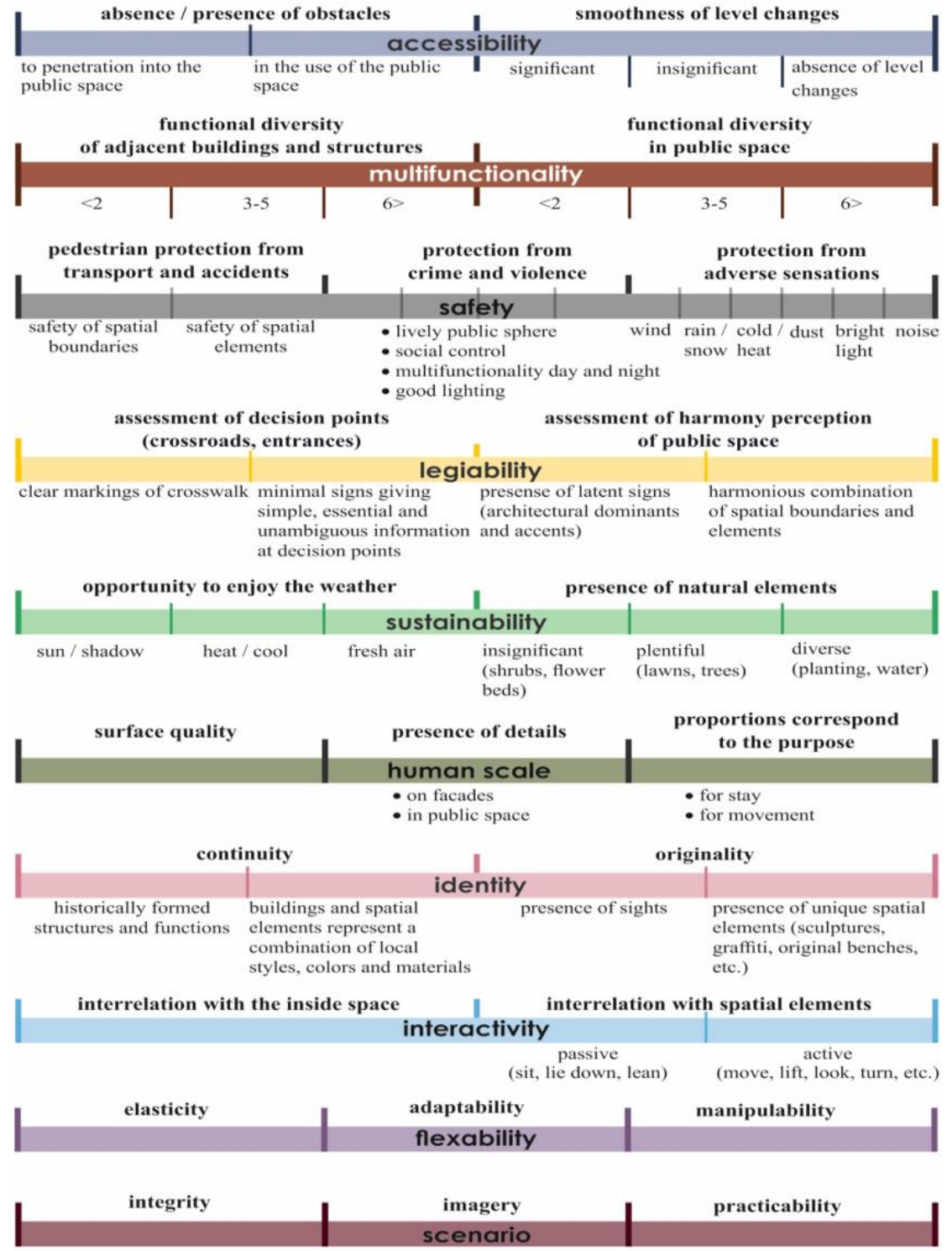

Fig. 1. Quality criteria for public spaces.

\section{Results}

The set of characteristics given below has the defining value for the public space of the city, in the absence of which space ceases to be public.

Accessibility refers to the degree of free access, penetration and use of public space for all, regardless of any physical or mental impairment. On a city-wide scale the principle of accessibility is refer to the connectivity of the city's districts, the regularity of traffic and the ergonomics of public transport and stopping points. On a district scale accessibility is 
expressed in terms of porosity of the block structure and pedestrian accessibility of basic public functions.

Multifunctionality refers to the degree of functional diversity and the possibility of choosing in public space. Only a diverse, mutually beneficial and complex mixture of places of residence, leisure, trade and other functional urban subsystems can ensure the build-up of social capital in the city [9]. It should be noted that the principle of multifunctionality is important for spaces of regional and citywide importance. Tranquil local spaces with a limited set of functions are important for maintaining a balance of use and emphasizing the significance of the higher status spaces.

Safety refers to the degree of security of a person in public space. Social control is the defining indicator for protection from crime in public spaces. City is safer then more people go out and spend time in public areas. A city that invites people to actively use of public spaces should offer them safe walking routes and active polymorph public nodes. Safety of linear spaces consists of the pedestrian protection from fear to stumble or fall, be crushed by the car or attacked. The safety of nodal spaces depends more on the ability to protect themselves from unpleasant conditions (wind, rain, cold, dust, noise, etc.).

Legibility refers to the degree of orientation convenience in the public space. Legible public spaces have a simple network of routes and intersections with simple unambiguous signs and visible unambiguous features. The key value of this term for the first time urban planning said Kevin Lynch (1960). He defined it as "the ease with which parts of the urban landscape are recognized and formed into an orderly picture", giving the legibility of the urban landscape a key value for creating an integral picture of the city, district or individual space [10, p 16]. From the standpoint of legibility a clear hierarchy of public spaces is important.

Sustainability refers to the degree of creation of a friendly environmental situation and the satisfaction of needs without damage to the environment. The city of Irkutsk for a dozen years is included in the Priority List of Russian cities with a high average level of atmospheric pollution [11]. In today's busy, noisy and aggressive communication environment of the city, a person is tired of aggression and strives for seclusion and silence. Given this feature of large cities will increase the need for spaces hidden from heavy traffic (pedestrian streets, parks). Expanding the network of such spaces in the city structure helps to reduce noise, air pollution and create a cozy atmosphere for the people. Such network is comfortable from the ecological point of view and contributes to the development of the permeability and safety public spaces. It is necessary to design public spaces as ecosystems in which elements created by man interact with natural ones. Ecological solutions (permeable sidewalks, bio-drainage systems) contribute to the sustainable development and improvement of the urban environment [12].

Human scale refers to the degree of creation proportionally comfortable environment for the people, characterized by the proportion of parts and the whole with the man and design goals [13]. The scale of space is characterized by its dimensions, the proportions of spatial boundaries and their detailing. Dimensions determine the size of the space pertaining to a person, its purpose (monumental / chamber) and the nature of social interaction in it (personal, social, public) [14, p 47]. One space (area, street, etc.) often combines several characters of social interaction.

Identity refers to the extent to which spaces reflect a local character and possess such a combination of functions, forms of development, characteristics, colors and materials that form their own identity in the general character of the area. Geographical and naturallyspatial context, history and cultural measurement form the image of the place i.e. genius loci. These particularities are bound with concrete space directly, its origin and development, natural-spatial conditions, particularities, which are not carried on the other place. The qualitative spaces promote in forming the individual profile of the place on the form and functions, in estimation of the associations and usages. Peculiarity, individual use of the city 
space are add an identity for the place, territorial, habitable, assists to build familiarity of the place, semantic orientation and locality of the public space.

Interactivity refers to the degree of people involvement in the active life of the city and in the processes occurring in public spaces. Therefore, it is necessary that processes take place, and participation in them is possible, desirable and encouraged. Because of the diverse and casual nature of activities, that take place in the public spaces, they require a space which has a subtle balance of being defined and yet not too defined, so that any activity which is natural to the neighbourhood at any given time can develop freely and yet has something to start from. Such a balanced will interest the users of space and give them the opportunity to interact with the environment and its elements [15].

Flexibility refers to the degree of variability in the urban environment. On the basis of Lynch's research, three indicators of flexibility can be distinguished: adaptability, elasticity and manipulability. He revealed it from the standpoint of urban planning and private spaces. Consider these indicators in relation to public space.

Adaptability is a measure of accordance determined by openness to development. Flexibility to change creates a great attraction of the place. In this case, flexibility accommodates two polar states: variability and stability. Adaptability is expressed in the degree of which modern needs and tendencies find their response in a particular space. In example the response to internet addiction was the spread of free WI-FI zones in public spaces to attract visitors, and the development of cycling entails the need to place bike parks in certain places.

Elasticity is an ability to return to the original state, i.e. time spatial changes. This scenography of space on holidays, changes in its functioning (Sunday fair, the overlapping of the car traffic in favour of pedestrians) and other temporary inclusions in space.

Manipulability is an ability to change the spatial environment in its form or use. The equipping of public spaces with elements with a variability of use significantly enriches the space. Events are another way to revitalize space, allow a new look at the familiar surroundings. "When a place and an event connected, they reinforce each other creating a heightened experience of the present moment" [4, p 120]. Despite their short duration of the temporary inclusions, their importance for the public space cannot belittle.

Scenario refers to the degree of spatial unity and semantic fullness created by the spatial concept. In the citywide structure scenario revealed in the presence of a strategy for the development of public spaces as an integral part of urban policy. World experience shows that the basis for successful renovation of developed modern cities was the existence of the concept of public spaces development and its gradual implementation [3]. Scenario on a district scale is the concept of organizing a network of public spaces in its structure.

The construction of an architectural scenario on a separate space scale is oriented toward predicting the human behaviour in a spatial-planning framework of the city. Many researchers $[14,16,17,18]$ note that if people hurries or works they interested in utilitarian qualities of the environment, if the behaviour is less purposeful, then socio-cultural and architectural qualities begin to acquire a greater importance. The script combines the functional and emotional aspects of the organization of space. Functionality consists in creating physically comfortable conditions for stay and movement in space. Emotionality refers to the degree of creation of spatial unity and semantic fullness, created through a spatial concept.

\section{Discussion}

Each spatial quality has its own criteria. By the criteria can be judged how much space corresponds to it. Estimating the space for all the qualities can be drawn conclusions about 
which of them needs special attention and perfection. Based on the results of studies of separate public spaces of the historical city center is possible to see the qualitative state both, the individual space and the historical center of the city as a whole.

During the research was made the qualitative assessment of the most characteristic public spaces of historical center of Irkutsk (Figure 2). Legibility, identity, human scale and stability proved to be the most developed qualities. Accessibility problems associated with level changes rank this quality on the fifth position. Following are the qualities of safety and functionality that are close in value. Low rates for these qualities are due to the lack of functional diversity in public spaces, which reduces the intensity of their use and does not allow for the provision of permanent social control. The most undeveloped qualities are interactivity and flexibility.

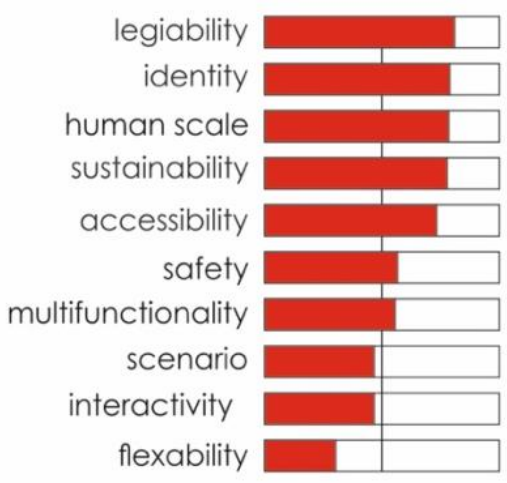

Fig. 2. Hierarchy of the qualities of public spaces of historical center of Irkutsk (based on the study of fourteen the most characteristic public spaces of Irkutsk).

These qualities did not have normative indicators of application so they are not given importance during the creation of public spaces. It should be noted than in conditions of the Siberian climate these qualities are able to ensure the viability of public spaces. The poorly developed quality of the scenario of public space is justified by the lack of meaningful fullness and uniform stylistics of space, supported by spatial elements.

\section{Conclusions}

On the basis of the conducted researches it is possible to give following recommendations on complex improvement of public spaces of a large city. On the scale of the city the following aspects are important in the implementation of the policy of the public spaces development: 1. The connectivity and comfort of the communication spaces of the city for all traffic participants with priority of pedestrians and public transport; 2 . Improvement the quality and functional diversity of regional importance public spaces; 3 . Forming the image of peripheral areas of the city through the style unity of spatial elements of the regional importance public spaces; 4. Involvement of local residents in the process of creating and improving public spaces; 5. Increase of the importance of park territories in the system of public spaces of the city; 6 . Preserving the short distance city; 7. Regular holding of city-wide events in different public spaces of the city; 8 . Overall concept for the development of public spaces of the city.

On the scale of the area of the historical center it is important to create a network of interconnected public spaces: 1. Accessibility of the communication structure of public spaces to the people with disabilities; 2 . Striving to the equivalence of open and closed public spaces in active nodes; 3 . Uniform distribution of housing and active functions at late evening 
hours; 4. Preservation and revitalization of the historical and cultural environment as the basis for the visual attractiveness and identity of the public spaces of the historical center; 5 . Creation of "green" routes, inviting to an active way of life (walking, playing sports, playing); 6 . Using the potential of courtyards adjacent to the main streets of the city; 7. Inclusion of the modern innovations in existing public spaces; 8 . The concept of public spaces development in the structure of the district.

Each public space need its own recipe but based on the generalization of the qualitative analysis conducted results, can be singled out the following main recommendations for improving public spaces in the historical center of a large Siberian city: 1. Functional variability of public spaces accordingly to the season changes; 2 . Creation the conditions for the use of spaces under different weather; 3 . Temporary inclusion on the environment: as a response to current trends, on public holidays, as an event; 4 . Soft borders; 5 . The inclusion of a variety of elements that create the prerequisites for the active use of public spaces; 6 . Meaningful space.

Summing up the recommendations, it can be noted that at this stage Irkutsk needs the formation of an interconnected network of public spaces that have interactive qualities, inviting people to active interaction and the ability to change.

\section{References}

1. A. Viljoen, K. Bohn, J. Howe Continuous productive urban landscapes: designing urban agriculture for sustainable cities (Oxford: Architectural Press, Elsevier, 2005)

2. E. Burton, L. Mitchell, Inclusive Urban Design. Streets for Life (Architectural Press, Elsevier, Oxford, 2006)

3. J. Gehl, L. Gemzøe, New city spaces (Danish Architectural Press, Copengagen, 2006)

4. K. Lynch, A theory of good city form (Stroyizdat, Moskow, 1986)

5. C. Moughtin, Urban design: street and square 3rd ed. (Architectural Press, Elsevier, Oxford, 2003)

6. N. Ellin, Integral Urbanism (Routledge Taylor \& Francis Group, New York, 2006).

7. J. Stankevic, Public Space Research report. Strelka institute for Media, Architecture and Design, 30-38 (2011)

8. L. V. Kozlova, Vestnik of Irkutsk State Technical University, 6 (101), 82-88 (2015)

9. J. Jacobs The Death and Life of Great American Cities (Random House, New York, 1961)

10. K. Lynch, The image of the city (Stroyizdat, Moskow, 1982)

11. Strategy of social and economic development of Irkutsk city up to 2025 (https://admirk.ru /DocLib/Стратегия\%20Иркутск\%20.pdf

12. NACTO 2015, Urban Street Design Guide transl., ed. V. Mylov (Moskow: Alpina nonfiction), 192 (2015)

13. V. T. Shimko, The architectural design of the urban environment tutorial (ArhitekturaS, Moskow, 2006)

14. J. Gehl, Cities for People (Island Press, 2010)

15. L. V. Kozlova, Proceedings of Irkutsk State Technical University, 6(89), 117-122 (2014).

16. A. Krasheninnikov, AMIT, 4 (21), 1-7 (2012)

17. N. A. Morgun, L. M. Reznitskaya, A. V. Skopintsev, Architectural scenography of the 
urban environment - as a design strategy for the reconstruction of the historical center of the city and the factor of strengthening its tourist image (http://archrus.ru/Activities/Statqi/ Arxitekturnaja-scenografija-gorodskoj-sredy)

18. W. H. Whyte City: Rediscovering the Center (University of Pennsylvania Press, Philadelphia, 2009) 